\title{
ANATOMIA DA MADEIRA DE CALYCOPHYLLUM CANDIDISSIMUM (VAHL) DC. (RUBIACEAE) ${ }^{1}$
}

\author{
TALITA BALDIN² JOSÉ NEWTON CARDOSO MARCHIORI ${ }^{3}$
}

\section{RESUMO}

São descritos e ilustrados os caracteres microscópicos da madeira de Calycophyllum candidissimum (Vahl) DC., destacando-se: vasos extremamente numerosos, em múltiplos radiais, menos comumente solitários e racemiformes; elementos vasculares de comprimento médio, com apêndices longos; parênquima axial ausente; raios heterogêneos, em sua maioria com 3 células de largura; e fibras libriformes septadas, de paredes delgadas a espessas.

Palavras-chave: Anatomia da madeira, Calycophyllum candidissimum, Ixoroideae, Rubiaceae.

\section{ABSTRACT}

[Wood anatomy of Calycophyllum candidissimum (Vahl) DC. (Rubiaceae)].

The wood microscopic features of Calycophyllum candidissimum (Vahl) DC. are described and illustrated, beeing outlined: extremely numerous porous, in radial multiples, less commonly round solitary and in clusters; medium length vascular elements; absent axial parenchyma; heterogeneous rays, mainly with three cells wide; and thin to thick walled libriform septate fibers

Kay words: Wood anatomy, Calycophyllum candidissimum, Ixoroideae, Rubiaceae.

\section{INTRODUÇÃO}

A família Rubiaceae é a quarta em número de espécies do Reino Vegetal, superada, apenas, por Orchidaceae Juss., Asteraceae Bercht. \& J.Presl e Fabaceae Lindl. (Mól, 2010). De distribuição cosmopolita, reúne cerca de 550 gêneros e 9.000 espécies (Judd et al., 2009), concentradas nas regiões mais quentes do globo (Chiquieri et al., 2004).

No Brasil, conforme Souza \& Lorenzi (2008), ocorrem cerca de 120 gêneros e 2.000 espécies, o que a torna a família uma das mais numerosas da flora nativa. Embora distribuída nas diversas formações vegetacionais, ela se encontra melhor representada na Mata Atlântica e, especialmente, no estrato arbustivo (Gomes, 1996).

1 Recebido em 04-8-2014 e aceito para publicação em 21-11-2014.

2 Engenheira Florestal, doutoranda do Programa de PósGraduação em Engenharia Florestal, Universidade Federal de Santa Maria. talita.baldin@ hotmail.com

3 Engenheiro Florestal, Professor Titular, Dr., Departamento de Ciências Florestais, Universidade Federal de Santa Maria. Bolsista de Produtividade em Pesquisa (CNPq-Brasil). marchiori@pq.cnpq.br
Sob o ponto de vista econômico, as Rubiaceae apresentam notável importância no setor farmacêutico, caso das espécies de Cinchona L. e Psychotria L. No setor ornamental, devido ao florescimento exuberante e beleza da copa, muitas espécies são utilizadas em paisagismo de parques e jardins, bem como na arborização de ruas e avenidas (Souza \& Lorenzi, 2008; Ribeiro et al., 1999). Para a produção de madeira, são relativamente poucas as espécies que atingem tamanho adequado à finalidade, destacando-se, nesse sentido, os gêneros Sarcomphalus P. Browne, Mitragyna Korth, Morinda L., Pausinystalia Pierre, Capirona Spruce, Calycophyllum DC. e Chimarrhis Jacq. (Mendoza et al., 2004).

O gênero Calycophyllum A. DC. insere-se, segundo Bremer (2009), na subfamília Ixoroideae e tribo Condamineeae, reunindo, até o presente momento, cerca de 20 binômios. Tratam-se de árvores de porte médio a grande, endêmicas da América tropical e, na flora brasileira, da região amazônica.

Calycophyllum candidissimum (Vahl) DC. recebe diversos nomes comuns, segundo a região: camarón, palo-camarón (México); surrá 
(Costa Rica); alazano (Panamá); guayabo (Colômbia); araguato, betún (Venezuela); e degame (Estados Unidos). As árvores, de porte pequeno a médio, habitam, preferencialmente, encostas úmidas e sombreadas, e são de fácil reconhecimento na época da floração, devido às sépalas foliáceas esbranquiçadas e muito conspícuas. Nativa de Cuba e América Central, desde o sul do México até a Colômbia e Venezuela, a espécie se mescla, no vale superior do Rio Negro (Brasil), com Calycophyllum obovatum (Ducke) Ducke. A madeira, de coloração escura e com massa específica de $0,67 \mathrm{~g} / \mathrm{cm}^{3}$, é de difícil trabalhabilidade e baixa resistência ao ataque de fungos, indicando-se para fabricação de proas, veículos e ferramentas (Record \& Hess, 1943).

É evidente a escassez de informações sobre espécies do gênero Calycophyllum, sobretudo do ponto de vista estrutural. A descrição anatômica de $C$. candidissimum, neste sentido, visa a sanar uma lacuna, e contribuir para o conhecimento anatômico da família Rubiaceae.

\section{REVISÃO DE LITERATURA}

Metcalfe \& Chalk (1972) registram as seguintes características anatômicas para Rubiaceae: vasos tipicamente pequenos, médios em alguns gêneros, numerosos a muito numerosos; poros exclusivamente solitários ou em múltiplos radiais de 4 ou mais, raramente com porosidade em anel; elementos vasculares de comprimento médio a longo; placas de perfuração simples; espessamentos espiralados ausentes; e pontoações ornamentadas, alternas, pequenas a diminutas.

Salvo exceções, o parênquima axial em Rubiáceas é tipicamente apotraqueal nas espécies com fibras não septadas, e ausente nas com septos em fibras. Os raios, estreitos e heterogêneos em $70 \%$ dos gêneros, apresentam 1-3 células de largura, com 4 ou mais fileiras marginais de células quadradas e eretas, mas até 8-10 células de largura em algumas espécies. As fibras, muito curtas a moderadamente longas, são providas ou não de septos, e apresentam pontoações simples ou areoladas (KoekNoorman, 1972).

Koek-Noorman (1977) e Jansen et al. (2002) classificam as madeiras de Rubiaceae em dois grupos: o "Tipo I", com poros predominantemente solitários, parênquima apotraqueal difuso, difuso-em-agregados e/ou em faixas, raios estreitos, com largas margens unisseriadas, e fibras não septadas, de pontoações distintamente areoladas; e o "Tipo II", com poros em múltiplos radiais, parênquima axial ausente ou paratraqueal escasso, raios grandes e fibras septadas, de pontoações simples.

O lenho de Calycophyllum dispõe de escassas informações, reforçando a necessidade de mais pesquisas. Record \& Hess (1943) citam, para o mesmo: vasos em múltiplos radiais, com 4 ou mais células; parênquima axial ausente; raios frequentemente de dois tamanhos distintos, com 4 ou mais células de largura, ocasionalmente com cristais; e fibras septadas.

\section{MATERIAL E MÉTODOS}

As amostras investigadas foram obtidas mediante permuta com o Instituto de Pesquisas Tecnológicas do estado de São Paulo (IPT) e a xiloteca da Black Forest Academy (BFA - Alemanha), constando, para as mesmas, os registros de número 6.009 e 10.583 , respectivamente.

Para confecção de lâminas de cortes anatômicos, foram extraídos três corpos-de-prova de cada amostra de madeira $(3 \times 3 \times 3 \mathrm{~cm})$, devidamente orientados para a obtenção de cortes nos planos transversal $(\mathrm{X})$, longitudinal radial (R) e longitudinal tangencial (T). Um quarto bloquinho foi também retirado, com vistas à maceração.

A montagem das lâminas seguiu a técnica padrão, recomendada por Burger \& Richter (1991): após fervura em água, os corpos-de-prova foram seccionados em micrótomo de deslizamento, regulado para a obtenção de cortes com espessura nominal de $18-20 \mu \mathrm{m}$; os cortes anatômicos foram coloridos ou com acridinavermelha, crisoidina e azul-de-astra, ou com 
safra-blau (safranina 30\% e azul-de-astra 70\%). $\mathrm{Na}$ sequência, os cortes foram desidratados em série alcoólica-ascendente $(30 \%, 50 \%, 70 \%$, $95 \%$, duas vezes em álcool absoluto), e transferidos a xilol. No preparo de lâminas permanentes, usou-se "Entellan" como meio de montagem. Para a dissociação do tecido lenhoso, seguiu-se o método de Franklin modificado (Kraus \& Arduin, 1997); a pasta foi colorida com safranina $1 \%$ e, na montagem de lâminas, usouse a mesma resina anteriormente referida.

A descrição qualitativa do lenho foi baseada nas recomendações do IAWA Committee (1989). A determinação da fração dos diferentes tecidos foi obtida com um contador de células, segundo a metodologia proposta por Marchiori (1980).

Os caracteres anatômicos foram medidos em microscópio binocular Carl Zeiss, provido de ocular com escala graduada, no Laboratório de Anatomia da Madeira da Universidade Federal de Santa Maria. As fotomicrografias foram tomadas em microscópio Leica DM 1000, equipado com câmera digital Olympus Camedia CX40, no Laboratório de Anatomia da Madeira da UFSM/CESNORS. O processamento das imagens foi realizado com o auxílio do programa CorelDRAW, X7 (64 Bit).

No texto descritivo, os dados quantitativos das características anatômicas referem-se à média (x) e desvio padrão (s), seguido pelos valores mínimo e máximo observados.

\section{DESCRIÇÃO ANATÔMICA}

Anéis de crescimento: distintos, marcados por 5 ou 6 fileiras de fibras radialmente estreitas e com paredes mais espessas, no lenho tardio, bem como pelo alargamento dos raios no limite do anel de crescimento (Figura 1A, B).

Vasos: extremamente numerosos $(163 \pm 19$ (126-202) poros $/ \mathrm{mm}^{2}$ ), ocupando $20 \%$ do volume da madeira. Porosidade difusa, uniforme, em arranjo radial. Vasos arredondados ou ovais (48 $\pm 9(28-65) \mu \mathrm{m})$, de paredes finas $(3 \pm 1(1-5)$ $\mu \mathrm{m})$, em múltiplos radiais de 2-9 (59\%), menos comumente solitários (34\%) ou racemiformes com 3-6 unidades (7\%); contato com células de raio, frequentes (Figura 1A, B). Elementos vasculares de comprimento médio (656 \pm 205 (190-1050) $\mu \mathrm{m})$, com placas de perfuração simples (Figura 1D), oblíquas, e apêndices longos (102 $\pm 64(30-340) \mu \mathrm{m})$, em ambas ou em apenas uma extremidade. Pontoações intervasculares pequenas, arredondadas ( $5 \pm 1$ (4-8) $\mu \mathrm{m})$, alternas, com abertura horizontal, lenticular, inclusa, ornamentada. Pontoações raio-vasculares, semelhantes às intervasculares, embora menores $(3 \pm 1(3-5) \mu \mathrm{m})$. Tilos, espessamentos helicoidais, estriações e depósitos, ausentes.

Parênquima axial: ausente.

Raios: numerosos (14 \pm 2 (9-20) raios/mm), heterogêneos e de dois tamanhos distintos, representando $32 \%$ do volume da madeira. Os unisseriados (15\%), de células quadradas e eretas, por vezes, procumbentes; de $288 \pm 106$ (150650) $\mu \mathrm{m}$ de altura, com $5 \pm 3$ (1-12) células, e $13 \pm 3(8-20) \mu \mathrm{m}$ de largura. Os multisseriados, em sua maioria trisseriados $(57 \%)$, menos comumente bisseriados (16\%) e tetrasseriados (12\%) (Figura 1E). Compostos de células procumbentes, no corpo central (5-19 células), reunem células quadradase eretas (Figura 1C) em curta fileira marginal (1-5 células); de 457 \pm 106 (190-620) $\mu \mathrm{m}$ de altura, com $16 \pm 4$ (8$25)$ células, e $33 \pm 6$ (15-50) $\mu \mathrm{m}$ de largura. Raios fusionados, presentes; raios agregados, ausentes. Células perfuradas, presentes (Figura 4D); células latericuliformes, envolventes e oleíferas, ausentes.

Fibras: libriformes, septadas (Figura 1F), de comprimento médio (1435 \pm 286 (910 - 2000) $\mu \mathrm{m})$ e paredes delgadas a espessas (6 \pm 1 (4 - 9) $\mu \mathrm{m})$; pontoações simples, com abertura verti$\mathrm{cal}$, restritas às faces radiais da parede. $\mathrm{O}$ tecido fibroso ocupa $48 \%$ do volume da madeira. Fibras gelatinosas, espessamentos helicoidais e traqueóides, ausentes.

Outros caracteres: cristais, em forma de areia (microcristais) e depósitos, presentes em células de raio (Figura 1C). Canais celulares, cistos glandulares, estrutura estratificada, sílica, 

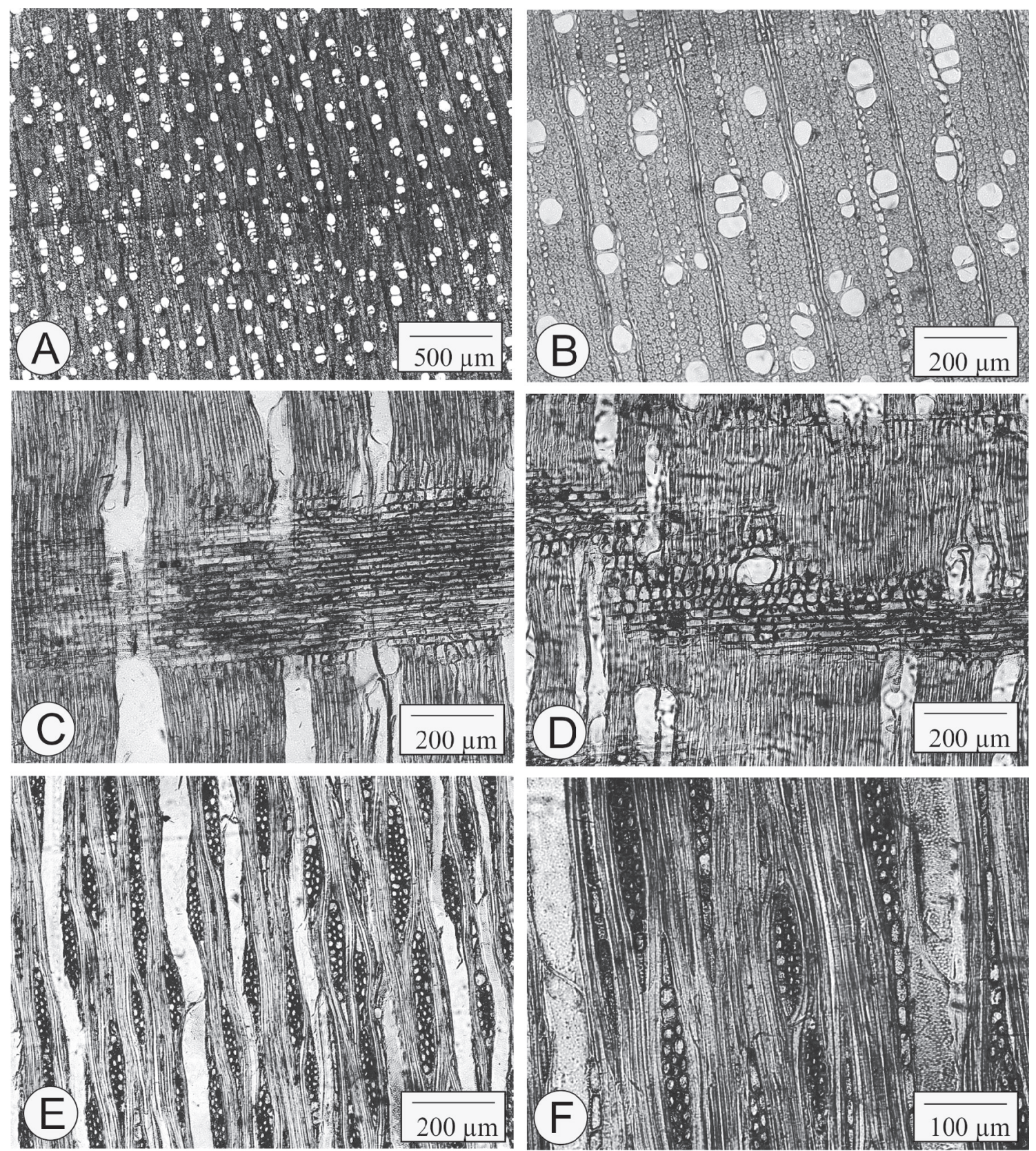

FIGURA 1- Aspectos anatômicos do lenho de Calycophyllum candidissimum. A - Limite de anel de crescimento, porosidade difusa, poros extremamente numerosos, solitários, em múltiplos radiais e com escassos racemiformes (seção transversal). B - Poros arredondados ou ovais, em frequente contato com células de raio, e fibras de paredes espessas no lenho tardio (seção transversal). C - Raio heterogêneo, com células procumbentes, no centro, e margens de células quadradas e eretas, com abundantes depósitos (seção longitudinal radial). D - Célula perfurada de raio (seta) e elementos vasculares com placas de perfuração simples (seção longitudinal radial). E-Raios uni a tetrasseriados (seção longitudinal tangencial). F - Mesma seção, em maior aumento, evidenciando fibras libriformes septadas. 
floema incluso, células oleíferas, células mucilaginosas e máculas medulares, ausentes.

\section{ANÁLISE ANATÔMICA}

As principais características do lenho de Calycophyllum candidissimum estão de acordo com as possibilidades estruturais relacionadas por Record \& Hess (1949), Koek-Noorman (1972) e Metcalfe \& Chalk (1972) para o conjunto das Rubiaceae.

A estrutura anatômica, por sua vez, insere a espécie no "Tipo II" de Rubiaceae, de acordo com Koek-Noorman (1977) e Jansen et al. (2002), devido à presença de: poros em múltiplos radiais; parênquima axial ausente; raios grandes (2-4 células, ou mais), com poucas camadas de células quadradas e eretas nas margens; e fibras septadas, com pontoações simples.

Quanto ao posicionamento interno na família, a espécie não atende aos padrões citados por Koek-Noorman (1972) e Jansen et al. (1997, 1999) para Ixoroideae: vasos solitários ou, menos comumente, em pequenos múltiplos radiais; fibrotraqueóides; e parênquima axial difuso, difuso-em-agregados ou em pequenas linhas marginais.

O material em estudo, por sua vez, coincide com as características anatômicas relacionadas por Léon (2011) para exemplares da mesma espécie, procedentes da Venezuela: anéis de crescimento indistintos ou marcados, ligeiramente, pela redução do diâmetro radial de fibras; porosidade difusa; vasos solitários e em múltiplos radiais de 2-8; placas de perfuração simples; pontoações intervasculares alternas, diminutas a pequenas; pontoado raio-vascular, semelhante; depósitos de gomo-resina, ocasionalmente presentes; fibras septadas com paredes espessas a muito espessas e pontoações indistintamente areoladas; parênquima paratraqueal escasso; raios heterogêneos, com mais de quatro fileiras marginais de células quadradas e eretas; células perfuradas de raio e areia cristalina, presentes na estrutura radial.

Cabe salientar que a ocorrência de células perfuradas de raio e de areia cristalina, obser- vadas no material em estudo, não foram registradas para a espécie por autores como Kribs (1968), Koek-Noorman (1972) e Nardi \& Edlmann (1992). Carlquist (1988), entretanto, inclui Calycophyllum entre os gêneros de Rubiaceae que apresentam areia cristalina em células de raio, sem menção, contudo, a espécies.

Em Calycophyllum candidissimum não se observou a presença de tilos, ao contrário do afirmado por Tortorelli (1956) e Richter \& Dallwitz (2009), que registraram o caráter para Calycophyllum multiflorum Griseb. A ausência desse aspecto anatômico pode ser atribuída ao reduzido diâmetro de vasos $(<100 \mu \mathrm{m})$ e pontoações, com valor médio de $5 \mu \mathrm{m}$, limitando a formação de tiloses, segundo Appezzato-daGlória \& Carmello-Guerreiro (2003).

A presença de gomo-resina não foi evidenciada na anatomia descritiva de Calycophyllum candidissimum. Léon (2011), todavia, em seus estudos com Rubiáceas da Venezuela, reporta a ocorrência do carácter para C. candidissimum, bem como para Amaioua corymbosa Kunth., A. guianensis Aubl., Duroia fusifera Hook.f. ex K.Schum., e Alseis labatioides H.Karst. ex K.Schum, entre outras espécies. Vale lembrar que depósitos de gomo-resina apresentam ampla ocorrência na família, conforme Metcalfe \& Chalk (1972) e Record \& Hess (1943).

\section{REFERÊNCIAS BIBLIOGRÁFICAS}

APPEZZATO-DA-GLÓRIA, B.; CARMELLOGUERREIRO, S. M. Anatomia vegetal. Viçosa: UFV, 2003. 438 p.

BURGER, L. M.; RICHTER, H. G. Anatomia da Madeira. São Paulo: Ed. Nobel. 1991. 154 p.

BREMER, B.; ERIKSSON, O. Time tree of Rubiaceae: phylogeny and dating the family, subfamily, and tribes. International Journal of Plant Science, v. 170, p. 766-793, 2009.

CARLQUIST, S. Comparative wood anatomy: systematic ecological and evolutionary aspects of dicotyledonean wood. Berlin: SpringerVerlag, 1988. $15 \mathrm{p}$. 
CHIQUIERI, A.; DI MAIO, F. R.; PEIXOTO, A. L. A distribuição geográfica da família Rubiaceae Juss. na Flora Brasiliensis de Martius. Rodriguésia, v. 55 (84), p. 47-57, 2004.

GOMES, M. Rubiaceae. In: LIMA, M. P. M. de; GUEDES-BRUNI, R. R. (Org.). Reserva ecológica de Macaé de Cima, Nova Friburgo-RJ: Aspectos Florísticos das espécies vasculares. Rio de Janeiro: Jardim Botânico, 1996. v. 2, p. 345426.

IAWA COMMITTEE. IAWA list of microscopic features for hardwood identificacion. IAWA Bulletin, v. 10, n. 3, p. 218-359, 1989.

JANSEN, S. E.; ROBBRECHT, H.; BEECKMAN \& SMETS, E. Comparative wood anatomy of African Coffeeae (Rubiaceae-Ixoroideae). Belg. J. Bot. 130: 47-58. 1997.

JANSEN, S.; BLOCK, P.; BEECKMAN, H.; SMETS, E. Systematic wood anatomy of the Pavetteae (Rubiaceae-Ixoroideae). Syst. Geogr, v. 68, p. 113-133. 1999.

JANSEN, S.; ROBBRECHT, E.; BEECKMAN, H.; SMETS, E. A survey of the systematic wood of the Rubiaceae. IAWA Bulletin, v. 23, n. 1, p. 167, 2002.

JUDD, W. S.; CAMPBELL, C. S.; KELLOGG, E. A. Sistemática vegetal: Um enfoque Filogenético. 3. ed. Porto Alegre: Artmed, p. 471-475. 2009.

KOEK-NOORMAN, J. Systematische holzanatomie einiger Rubiaceen. Ber. Deut. Bot. Ges., v. 90, p. 183-190, 1977.

KOEK-NOORMAN, J. The Wood Anatomy of Gardeniae, Ixoreae and Mussaendeae (Rubiaceae). Acta Botanica Neerlandica, v. 21, n. 3, p. 301-320, 1972.

KRAUS, J. E.; ARDUIN, M. Manual básico de métodos em morfologia vegetal. Rio de Janeiro: EDUR, 1997. 198 p.

KRIBS, D. Comercial foreign woods on the American market. Dover Publications Inc. New York. 1968. $241 \mathrm{p}$.

LEÓN. H., WILLIAMS J. Anatomía de la madera de 31 especies de Rubiaceae en Venezuela. Acta Botánica Venezuelica, v. 34, n. 2, p. 347-379, 2011.

MARCHIORI, J. N. C. Estudo anatômico do xilema secundário de algumas espécies dos gêneros Acacia e Mimosa, nativas no estado do Rio
Grande do Sul. 1980. 186 f. Dissertação (Mestrado em Engenharia Florestal) - Universidade Federal do Paraná, Curitiba, 1980.

MENDOZA, H.; RAMÍREZ, B.; JIMÉNEZ, L. C. Rubiaceae de Colombia: Guía ilustrada de géneros. Instituto de Investigación de Recursos Biológicos Alexander von Humboldt. Bogotá, Colombia. 2004. 351 p

METCALFE, C.R.; CHALK, L. Anatomy of the Dicotyledons. Oxford: Clarendon Press, 1972. $1500 \mathrm{p}$.

MÓL, F. F. D. Rubiaceae em um remanescente de floresta atlântica no Rio Grande do Norte, Brasil. 2010. 116 f. Dissertação (Pós-Graduação em Ciências Biológicas) - Universidade Federal do Rio Grande do Norte, Natal, 2010.

NARDI, R. B.; EDLMANN, A. M. Legnami tropicali importati in Italia: anatomia e identificazione. vol. II. América Latina. Istituto di Assestamento e Tecnología Forestale. Firenze, Italia. 1992.

RECORD, S. J.; HESS, R. W. Timbers of the New World. New Haven: Yale University Press, 1943. $640 \mathrm{p}$.

RECORD, S. J., HESS, R. W. Timbers of The New World. New Haven: Yale University Press, 1949. $640 \mathrm{p}$.

RIBEIRO, J. E. L. da S.; HOPKINS, M. J. G.; VICENTINI, A.; SOTHERS, C. A.; COSTA, M. A. S.; BRITO, J. M. de; SOUZA, M. A. D.; MARTINS, L. H. P.; LOHMAN. L. G.; ASSUNÇÃO, P. A. C. L.; PEREIRA, E. C.; SILVA, C. F.; MESQUISTA, M. R.; PROCÓPIO, L. C. Flora da Reserva Ducke: Guia de identificação das plantas vasculares de uma floresta de terrafirmena Amazônia Central. Manaus: INPA. 1999. $799 \mathrm{p}$.

RICHTER, H. G.; DALLWITZ, M. J. 2000 onwards. Commercial timbers: descriptions, illustrations, identification, and information retrieval. In English, French, German, Portuguese and Spanish. Version: 25th June 2009 "http://deltaintkey.com'.

SOUZA, V. C.; LORENZI, H. Botânica Sistemática: Guia ilustrado para identificação das famílias de Fanerógamas nativas e exóticas no Brasil, baseado em APG II. 2. ed. Nova Odessa, São Paulo: Instituto Plantarum. 2008. 768 p.

TORTORELLI, L. A. Maderas y bosques argentinos. Buenos Aires: ACME, 1956. 910 p. 